\title{
De la omnipresencia de la imagen a su \\ ausencia en la enseñanza de ele: estudio comparativo entre Francia y Gabón
}

\author{
Ibinga, Marcelle \\ CRAAL, E.N.S. / Libreville-Gabón \\ Punues66@yahoo.fr
}

Ndzang Nyangone, Hilaire

CRAAL, E.N.S./Libreville-Gabón

hilairenyangone@gmail.com

\section{Resumen}

En los sistemas educativos occidentales, la imagen es solicitada del mismo modo que el texto en la enseñanza y el aprendizaje de las lenguas extranjeras de las cuales el español. Esta valoración de la imagen es debida a su carácter comunicacional y al interés que los jóvenes dan a este tipo de soportes. Sin embargo, a pesar de esta valoración de la imagen en Occidente, quedan muchos sistemas educativos por el mundo que no explotan todavía suficientemente la imagen. Es el caso de Gabón donde la enseñanza y el aprendizaje del español, por ejemplo, se hacen casi exclusivamente a partir del texto mientras existen instrucciones oficiales que recomiendan la diversificación de los soportes y la valoración de la iconografía. Dado que el sistema educativo gabonés es modelado por el sistema francés, y que Francia y Gabón ilustran perfectamente esta oposición entre la omnipresencia de la imagen en los programas franceses y su ausencia en los programas gaboneses; queremos cuestionar ambos sistemas educativos para destacar las causas de la negligencia de la imagen en la enseñanza y el aprendizaje de ELE en Gabón.

Para conseguir nuestro objetivo, cuestionaremos lo que prevalecen los manuales El Marco común europeo y Horizontes y a los alumnos de la segundaria respecto al uso de la imagen en la enseñanza y el aprendizaje de ELE. El interés de este trabajo es llevar a que los docentes de ELE de Gabón cambien de actitud frente al documento iconográfico.

\section{Abstract}

In Western educational systems, the image is requested in the same way as the text in the teaching and learning of foreign languages of which Spanish. This assessment of the image is due to its communicational nature and the interest that young people give to this type of media. However, despite this assessment of the image in the West, there are many educational systems around the world that still do not exploit the image sufficiently. This is the case of Gabon, where the teaching and learning of Spanish, for example, are almost exclusively done from the text while there are official instructions that recommend the diversification of the supports and the valuation of the iconography. Given that the Gabonese educational system is shaped by the French system, and that France and Gabon perfectly illustrate this opposition between the omnipresence of image in French programs and their absence in Gabonese programs; We want to question both educational systems to highlight the causes of the negligence of the image in the teaching and learning of ELE in Gabon.

To achieve our goal, we will question what prevails the European Common Framework and Horizons manuals and secondary school students regarding the use of the image in the teaching and learning of ELE. The interest of this work is to make teachers of ELE in Gabon change their attitude towards the iconographic document.

Palabras clave: Ausencia, Enseñanza, Estudio comparado, Francia, Gabón.

Keywords: Absence, Teaching, Comparative study, France, Gabon. 


\section{INTRODUCCIÓN}

Tras su independencia negociada ${ }^{3}$ con su antigua metrópoli en 1960 (H. Ndzang Nyangone, 2014: 220), el sistema educativo gabonés se inspira del de Francia. En la enseñanza/aprendizaje del español, las similitudes entre ambos sistemas educativos se manifiestan no sólo a nivel de los contenidos, sino también a el de los soportes didácticos usados. Por lo que conciernen los soportes, en las instrucciones oficiales ${ }^{4}$ gabonesas, se recomienda un uso equilibrado de los textos y de las imágenes. Desgraciadamente, se notan unas diferencias formales entre las prácticas de clase en Francia y las de Gabón. En efecto, a la diferencia de Francia donde las imágenes y los textos se usan en la enseñanza/aprendizaje de las lenguas extranjeras, se nota un desequilibrio creciente en Gabón entre el uso de los documentos iconográficos y él de los soportes textuales. En otras palabras, la mayoría de los docentes gaboneses de lenguas extrajeras, en general, y de ELE, en particular, parecen utilizar más los soportes textuales (H. Ndzang Nyangone, 2018).

Esta oposición entre el modelo francés del que se inspira el sistema educativo gabonés, y el desequilibrio entre la teoría que recomienda una mejor valoración de los soportes iconográficos y la práctica en la que la iconografía es casi ausente, es lo que justifica la elección de este tema. Por eso, queremos demostrar que en Gabón existe una oposición entre las instrucciones oficiales que recomiendan vivamente el uso de documentos iconográficos en la enseñanza de las lenguas extranjeras, y la práctica de clase de los docentes gaboneses de ELE en la que la iconografía es casi ausente. Además de subrayar estas oposiciones, queremos poner de relieve su impacto en la enseñanza/aprendizaje del español en Gabón. Así, compararemos los contenidos de unos manuales franceses y gaboneses de ELE en cuanto a la iconografía con la meta de luchar contra el desinterés de los aprendices gaboneses debido a la monotonía de las clases de ELE.

En el estudio que sigue, clarificaremos primero los conceptos y presentaremos nuestra problemática. A continuación, indicaremos nuestra opción metodológica así como los resultados conseguidos a lo largo de nuestras investigaciones. Por fin, formularemos unas sugerencias para reparar el problema que planteamos.

\section{CLARIFICACIÓN DE LOS CONCEPTOS Y PROBLEMÁTICA}

Esta parte se compone de tres puntos esenciales de los cuales la definición de los conceptos y la presentación de la problemática. Estos primeros puntos serán seguidos de una breve comparación de la pedagogía por la imagen en Francia y en Gabón.

\subsection{Marco definicional de los conceptos}

Dentro de los conceptos que queremos clarificar figuran la omnipresencia, la ausencia, la imagen y el ELE. Si tomamos el caso del primer término, la omnipresencia, remite generalmente en una súper presencia de algo o de alguien en un espacio preciso. Al relacionarlo con la temática de esta reflexión, la omnipresencia evoca una súper presencia de la imagen en la enseñanza y el aprendizaje del español lengua extranjera. En otros términos, es una utilización efectiva de la iconografía en la enseñanza de ELE. Con esta aceptación, la omnipresencia se opone diametralmente a la ausencia que significa la no presencia o la no utilización de la imagen en la enseñanza de ELE.

\footnotetext{
${ }^{1}$ Centro de Investigación para las Artes y las Lenguas.

2 Escuela Normal Superior.

${ }^{3}$ A la diferencia de las naciones latinoamericanas y de unas naciones africanas que lucharon con la antigua metrópolis para independizarse, Gabón y otras antiguas colonias francesas de África optaron por una negoción con la antigua potencia colonizadora. Una de las resoluciones de estas negociones es evidentemente la elección del francés como lengua de la enseñanza.

${ }^{4}$ Las principales instrucciones oficiales que rigen la enseñanza y el aprendizaje de las lenguas extranjeras en Gabón son: La ley de orientación y La carta de orientación. Estos dos soportes jurídicos contienen todas las informaciones necesarias a los objetivos de la enseñanza de las lenguas extranjeras en Gabón así como a los contenidos de dichas enseñanzas.
} 
En cuanto a la imagen, es de recordar que este vocablo emana originalmente del griego eikon, imagen y graphia, grafía para significar primero el arte del dibujo ( A. Goliot-Lété, M. Joly, T. Lancien y al, 2006:180). Pero esta palabra puede tener muchas significaciones. Relacionado con un personaje, una época, un movimiento filosófico, o una religión, la iconografía designa el estudio de sus diferentes representaciones visuales. Por extensión, este término designa también el corpus de estas representaciones. Cuando dichas representaciones visuales son clasificadas: se habla por ejemplo de la iconografía de un santo o de una época (Ibid.).

Desde el siglo XX, el sentido de la palabra evoluciona para designar finalmente el conjunto de imágenes o de representaciones visuales. Esta aceptación es la que se aproxima más del objetivo de éste: la pedagogía por la imagen, o más precisamente la enseñanza y el aprendizaje del español por la imagen. Eso nos lleva a la problemática central de este artículo.

\subsection{Problemática}

Al formular esta temática, partimos de la constatación según la que, desde tiempos remotos, la imagen siempre ha permitido a los hombres comunicar entre sí. Nos apoyamos por esto sobre las imágenes primitivas pintadas o gravadas en las rocas o las piedras por los primeros hombres para comunicarse (M. Joly, 2002:122). Este carácter comunicacional de la imagen intrigó a los filósofos de los cuales Aristóteles y Platón que veían cada uno según su enfoque, en la imagen, una herramienta filosófica que podía conducir en la verdad o aislar de esta misma (H. Ndzang Nyangone:2018).Partiendo de los casos precisos de Francia y de Gabón, queremos saber si se toma efectivamente en cuenta este carácter cognitivo de la imagen en la enseñanza y el aprendizaje del español lengua extrajera.

De hecho, si la imagen es utilizada en la enseñanza/aprendizaje de las lenguas extranjeras en Francia, eso significa que ella debería también ser utilizada en el sistema educativo gabonés que se asimila tanto al modelo francés. Al comparar ambos sistemas educativos. No pretendemos juzgar lo que se hace en una u otra nación, sino tomar lo bueno que se hace en tal sistema educativo para aplicarlo en otro. Por eso, nos limitaremos al uso de la iconografía en la enseñanza y el aprendizaje de ELE.

Al formular esta temática, partimos de la constatación según la que, desde tiempos remotos, la imagen siempre ha permitido a los hombres comunicar entre sí. Nos apoyamos por esto sobre las imágenes primitivas pintadas o gravadas en las rocas o las piedras por los primeros hombres para comunicarse (M. Joly, 2002:122). Este carácter comunicacional de la imagen intrigó a los filósofos de los cuales Aristóteles y Platón que veían cada uno según su enfoque, en la imagen, una herramienta filosófica que podía conducir en la verdad o aislar de esta misma (H. Ndzang Nyangone:2018).Partiendo de los casos precisos de Francia y de Gabón, queremos saber si se toma efectivamente en cuenta este carácter cognitivo de la imagen en la enseñanza y el aprendizaje del español lengua extrajera.

De hecho, si la imagen es utilizada en la enseñanza/aprendizaje de las lenguas extranjeras en Francia, eso significa que ella debería también ser utilizada en el sistema educativo gabonés que se asimila tanto al modelo francés. Al comparar ambos sistemas educativos. No pretendemos juzgar lo que se hace en una u otra nación, sino tomar lo bueno que se hace en tal sistema educativo para aplicarlo en otro. Por eso, nos limitaremos al uso de la iconografía en la enseñanza y el aprendizaje de ELE.

\subsection{La pedagogía por la imagen en Francia y en Gabón}

Para conformarnos a nuestra problemática, intentaremos comparar el grado de utilización de los soportes iconográficos en la enseñanza/aprendizaje de ELE en Gabón y en Francia. Por esto, nos apoyaremos sobre las instrucciones académicas oficiales en vigor en ambos países a propósito del uso didáctico de la imagen. Más precisamente, nos interesaremos al Marco común europeo de referencia (MCERL), por el caso de Francia, y la Carta de Orientación para Gabón. 


\subsubsection{Caso de Francia}

La enseñanza/aprendizaje del español lengua extranjera son regidos por las instrucciones oficiales (el MCERL) que se aplican en la mejoría de los Estados de la Unión Europea. Este MCERL constituye un aporte considerable, pues proporciona una visión común elaborada por diferentes países en cuanto a la enseñanza/aprendizaje de lenguas extranjeras. Es un conjunto de orientaciones hecho de propuestas de actividades, de soportes, de registros, de clases y de materiales que dependen del público concernido (M. Yapassi, 2017:18).

\section{EI MCERL:}

Es un documento cuya concepción se resume como una herramienta de reflexión y no como una lista de consignas definitivas sobre el proceso de enseñanza/aprendizaje de la cual debemos fiarnos» (Cristian Lengara, 2013: 20).

De modo general, el MCERL no debe considerarse como una prescripción médica, sino como un guía que propone pistas viables para encontrar métodos adecuados de enseñanza/aprendizaje. Se utiliza en Francia como apoyo, y no como una recomendación como lo específica más bien su presentación y la nota usuario:

Hay que dejar claro desde el principio de que no nos proponemos decir a los profesionales lo que tienen que hacer o de qué forma hacerlo. Nosotros planteamos preguntas, no las contestamos. El marco común europeo de referencia no tiene el cometido de establecer los objetivos que deberían proponerse los usuarios ni los métodos que tienen que emplear (MCERL, 2002: 11).

Para volver a nuestra temática, el MCERL preconiza el uso de diferentes tipos de imágenes en clases de lenguas extranjeras. En sus líneas, aparece claramente que los recursos visuales y audiovisuales (la iconografía) facilitan las clases de lengua extranjera. Este beneficio se justifica esencialmente por su capacidad de crear contextos de aprendizaje y facilitan la expresión oral de los aprendices que deben expresar individualmente o en grupos por el medio de la lengua estudiada las impresiones y emociones suscitadas por la imagen interpretada.

Es en esta lógica que el MCERL dispone que los alumnos deben aprender una segunda lengua extranjera de diversas formas como, por ejemplo, oír conversaciones, escuchar la radio, ver la televisión, vídeos, o películas, etc. Además de estas sugerencias teóricas, el apartado 6.4.2 de dicho documento presenta opciones metodológicas para facilitar la explotación didáctica de documentos iconográficos en situación de enseñanza/aprendizaje de LE/L2 llamando la atención sobre el uso que se puede y se debería hacer de los recursos visuales y audiovisuales en situación de clase. Es por ejemplo en esta óptica que se precisa que:

El uso de recursos visuales y audiovisuales en la clase de segunda lengua ofrece enormes posibilidades. Uno de los objetivos de su utilización debe ser, abrir el estudiante a la realidad de la sociedad en la que se habla el idioma que quiere aprender puesto que, como se lo señalará en el capítulo II, la evolución en la enseñanza de las lenguas se ha encaminado en un enfoque mucho mas social, cultural y comunicativo. Por otra parte, los recursos visuales y audiovisuales no deben ser considerados como una actividad de ocio a la que se debe acudir cuando los estudiantes están cansados o poco motivados (MCERL 2002:73).

Como podemos constatarlo, el MCERL recomienda vivamente el uso de documentos iconográficos en la enseñanza y el aprendizaje de lenguas extranjeras en todos los países europeos en los cuales está aplicado. Para mucho completas, estas recomendaciones teóricas se acompañan de propuestas demológicas para facilitar y acompañar a los docentes en la explotación didáctica de soportes iconográficos. Los diferentes países de la Unión Europea que aplican estas recomendaciones las adaptan a sus realidades socioeducativas, culturales y políticas para concebir los manuales de LE/L2 utilizados en sus diferentes escuelas y universidades. Es el caso de Francia. Por esto, las imágenes son abundantemente utilizadas en el sistema educativo francés, en general, y en la enseñanza y el aprendizaje de las lenguas extranjeras de las cuales el español. ¿Cuál es el caso de Gabón en cuanto país cuyo sistema se inspira de Francia? 


\subsubsection{Caso de Gabón}

Como en Francia, la enseñanza/aprendizaje de ELE en Gabón, obedece a unas recomendaciones oficiales. Son generalmente reglas o advertencias cuya finalidad es la eficacia y la homogeneidad de las clases de lenguas extranjeras en todo el país. Se trata más precisamente de recomendaciones dictadas por el gobierno a través del Ministerio de la Educación, y materializadas por algunas instituciones nacionales como el Instituto Pedagógico Nacional (IPN), en colaboración con los consejeros pedagógicos y los docentes.

La meta conseguida es la elaboración de orientaciones relacionadas con los programas escolares. Sin pretender estudiar todas las orientaciones propuestas, nos limitaremos en las que se relacionan con la enseñanza de ELE y el uso de los soportes iconográficos.

Dicho esto, el departamento de español del Instituto Pedagógico Nacional ${ }^{5}$ preconiza directivas que se deben en el marco de la enseñanza/aprendizaje de ELE en Gabón. Se fijan unos objetivos de los cuales: los objetivos lingüístico y cultural, convencionalmente orientados hacia el mundo hispánico, pero dando un interés particular a los rasgos culturales gaboneses y africanos (M. Yapassi, 2017: 21). A los objetivos lingüísticos y culturales precitados se añade un objetivo comunicacional. Para alcanzar estos diferentes objetivos:

El alumno irá mejorando sus competencias lingüísticas al mismo tiempo que adquirirá conocimientos indispensables, que le abrirán al mundo hispánico. Esta tarea se conseguirá a partir de diversos documentos auténticos y de calidad que deben permitir al alumno desarrollar sus aptitudes analíticas y expresivas de modo personal basándose sobre datos reales (...) y cuando una misma idea está sobre diferentes perspectivas (E. Eyeang,1997:156).

La expresión "documentos auténticos y de calidad» utilizada en este fragmento invita a la diversificación de los soportes didácticos en la enseñanza y el aprendizaje de ELE en Gabón. Puede tratarse de soportes textuales, pero también de soportes visuales, sonoros y audiovisuales (la iconografía). Refiriéndose a los documentos iconográficos, las instancias pedagógicas gabonesas precisan que:

Aprender una lengua es también aprender a comprenderla cuando está hablada por locutores de diversos (no solo por el docente y los compañeros), hablada a un ritmo natural (...) las imágenes son muy presentes en la vida del alumnado. La pantalla de televisión ocupa una parte considerable de la jornada del alumno. Es un hecho social. Lo que el docente debe hacer, es contribuir a la educación iconográfica del alumno (IPN, 1991, 7-8)6.

Sin embargo, a la diferencia del MCERL, las instrucciones oficiales dictadas por las instancias pedagógicas gabonesas no formulan propuestas metodológicas capaces de acompañar y guiar al docente en la explotación didáctica de un soporte iconográfico. Así que, los docentes deben desembrollarse para intentar conseguir estos objetivos. Esta ausencia de enfoque metodológico relativo a la iconografía se confirma también en el manual de ELE Horizontes concebido por los africanos y para el alumnado africano, y que es generalmente utilizado en Gabón. Si queda claro que unas imágenes figuran en dicho manual, pero lamentamos la ausencia de propuestas metodológicas para acompañar al docente. Y cuando existen unas líneas que tratan de la imagen, se da la impresión de que todas las imágenes se analizan y se interpretan del mismo mundo. La consecuencia más inmediata de esta carencia metodológica es que los docentes gaboneses de lenguas extranjeras evitan los documentos iconográficos trabajando casi exclusivamente con los soportes textuales.

Ahora vamos a ver la metodología que nos ha permitido solucionar la problemática planteada.

\footnotetext{
${ }^{5}$ Esta institución dirige todas las instancias pedagógicas gabonesas fue creado en 1983.

6 "Apprendre une langue, c'est aussi apprendre à la comprendre quand elle est parlée par des locuteurs divers (pas seulement le professeur et les camarades), parlée à un rythme naturel (...) les images sont très présentes dans la vie quotidienne du jeune élève. Le petit écran occupe une bonne partie de la journée de l'élève. C'est un fait social. Ce que le professeur doit faire, c'est de contribuer à l'éducation iconographique de l'élève". La traducción es nuestra.
} 


\section{METODOLOGÍA}

\subsection{Instrumentos y población entrevistada}

Esta investigación es de tipo mixta, o sea cuantitativa y cualitativa en que hemos privilegiado dos técnicas de análisis de los contenidos: la investigación documentaria y las entrevistas semidirigidas que tuvimos con alumnos de la segundaria.

Con respecto a la primera técnica, comparamos las recomendaciones que se destacan del Marco Común Europeo de Referencia para las Lenguas (MCERL) y la Carta de Orientación de Gabón en cuanto al aprendizaje del español como lengua extranjera.

En cuanto a la segunda, nos ha llevado a recopilar las opiniones del alumnado gabonés sobre el uso de documentos iconográficos. Así que, la variable elegida para la discusión es «la importancia del estudio de la imagen en el aprendizaje de ELE en Gabón».

Hemos escogido las entrevistas porque ha sido difícil emprender la distribución de las encuestas. Ya que el periodo coincidía con la ida de los alumnos de vacaciones. Recoger estas encuestas hubiera sido complicado y la interpretación aún más.

Ha sido interesante discutir directamente con los alumnos porque recogimos la respuestas espontáneamente. Con este procedimiento podíamos volver a repetir las preguntas en el caso de que no hayan entendido las respuestas o que los alumnos no hayan captado bien nuestras preocupaciones. Lo que podemos lamentar es el hecho de no haber podido entrevistar a los alumnos de Francia por la distancia geográfica que separa Gabón de Francia.

En cuanto a la población entrevistada, elegimos tres niveles: $3^{\text {ième }}, 2^{\text {nde }}$ y Tle. El primer nivel son los que finalizan el primer ciclo; el segundo principian el segundo ciclo y el tercer nivel porque clausura los estudios segundarios.

En cuanto a la organización del trabajo, entrevistamos a quince (15) alumnos divididos en grupos de cinco (5) para cada nivel. Según los institutos, teníamos diez (10) para el instituto Paul Emane Eyeghe ( $3^{\text {ième }}$ y $2^{\text {nde }}$ y los cinco (5) del nivel Tle (son los que preparan el bachillerato) eran alumnos del instituto Nelson Mandela, todos los dos establecimientos son de Libreville, la capital de Gabón.

\subsection{Recopilación de datos de la investigación}

Como lo hemos señalado arriba, los datos los hemos recopilado del MCERL y de las Instrucciones oficiales del ministerio de la Educación de Gabón (Carta d'Orientation, 1995). Ya que:

Los textos oficiales de la enseñanza del español lengua extranjera han previsto el uso de la prensa como soporte didáctico entre la novela, la poesía, el teatro, los documentos iconográficos y sonoros (E. Eyeang, M. Ibinga, 2013:177).

Estas instrucciones dicen exactamente que se debe trabajar en clase de ELE: «l'étude de textes (littérature, presse), d'images (dessins, tableaux, gravures, photographies), d'enregistrement sonores et audiovisuels de qualité [...] (CNDP, 1995).

Por otra parte, iniciamos entrevistas semidirigidas con los alumnos de los institutos identificados arriba. Este procedimiento permite al entrevistado ajustar sus propósitos acaso quiera rectificar algún punto de vista. También este instrumento ha permitido saber lo que piensan los alumnos del uso de la imagen en clase de ELE y sobre todo lo que guardan de la clase de ELE cuando se trata de una imagen comparándola al estudio de texto. 


\subsection{Presentación e interpretación de los resultados}

Se trata aquí de interpretar las diferentes disposiciones legales sobre el uso de los documentos iconográficos y en seguida relacionarlas con los contenidos de los manuales de ELE en Francia y en Gabón. Luego las representaciones para con el uso de las imágenes en clase de ELE en Gabón parecen importantes para entender la importancia del estudio de este tipo de soporte didáctico.

\subsubsection{Presentación de los resultados}

Sobre las instrucciones de ambos países, relevamos que los países africanos entre los cuales se encuentra Gabón, no han podido adaptarse en las instrucciones internacionales, los contextos locales.

En lo relacionado con las entrevistas, al discutir con los diferentes alumnos, les dirigimos dos preguntas y sus respuestas las tenemos en estos dos cuadros abajo:

Cuadro 1: para saber cuántos estudian con documentos iconográficos.

Pregunta 1 ¿Estudiáis documentos iconográficos durante sus clases de español?

\begin{tabular}{|c|c|c|}
\hline Niveles & Sí & No \\
\hline 4ième & 1 & 4 \\
\hline 3ième & 2 & 3 \\
\hline 2nde & 0 & 5 \\
\hline Tle & 2 & 3 \\
\hline Total & 5 & 15 \\
\hline Porcentajes & $25 \%$ & $75 \%$ \\
\hline
\end{tabular}

Cuadro 2: para saber si les parece interesante o no aprender el español a partir de documentos iconográficos

Pregunta 2: ¿Qué os parece aprender el español con un documento iconográfico?

\begin{tabular}{|c|c|c|}
\hline Niveles & interesante & Aburrido \\
\hline 4ième & 5 & 0 \\
\hline 3ième & 5 & 0 \\
\hline 2nde & & \\
\hline Tle & 5 & 0 \\
\hline Total & 15 & 0 \\
\hline Porcentajes & $75 \%$ & $0 \%$ \\
\hline
\end{tabular}

\subsubsection{Interpretación de los resultados}

Los dos cuadros presentados precedentemente aluden a las respuestas de dos preguntas dirigidos a los alumnos. Se destaca del primer cuadro que sólo $25 \%$ de los alumnos han estudiado imágenes en clase de ELE. Este porcentaje revela efectivamente la falta de interés para con los documentos iconográficos. Esto puede significar que los docentes no saben cómo explotar este tipo de documentos.

En cuanto al segundo cuadro, se revela que la mayoría se encuentra animado trabajar con imágenes.

En lo que atañe a los datos obtenidos de las instrucciones oficiales de Francia y Gabón y la cualidad de las discusiones que tuvimos con los alumnos de los diferentes niveles identificados, existe una distancia entre los dos sistemas. 
Sobre las instrucciones del MCERL, diremos que son aplicadas y en Gabón la Carta de Orientación tiene insuficiencias en cuanto a cómo explotar el documento iconográfico. Gabón basta con «imitar los modelos occidentales, sin saber realmente lo que es importante o no para los africanos, causando así enormes problemas de adaptación» (Yapassi, ob.cit.: 18). Mientras si estamos en la imitación de modelos de Francia, hay que hacerlo con exactitud.

Con respecto a las entrevistas semidirigidas retenemos que todos los alumnos con quienes discutimos piensan que la clase de español es más viva cuando se trata de un documento iconográfico comparándolo al estudio de un texto. La razón que dan es que, las imágenes como los cuadros o aún publicidades, llaman su atención. Para ellos la interpretación es más objetiva porque se ve y se puede fácilmente comparar los objetos del documento. También piensan que trabajar con los textos les aburre mucho. Porque de vez en cuando hay textos que dificultan la comprensión, mientras con una foto o un cuadro, será como un juego. Con facilidad el alumnado describirá, explicará e interpretará lo que destaca del documento. «Cette démarche à pour objectif de rendre l'apprenant acteur de ses apprentissages afin de construire ses savoirs...» (H., Ndzang Nyangone, 2018: 53). Pero «sin perder pertenencia a la cultura inicial» M. Ibinga y E. Eyeang, 2014: 437). En esta perspectiva, «el docente va a ayudar (al alumno) a comunicar en más de una lengua extranjera y ponerles en disposiciones favorables para su formación» (M. Ibinga y E. Eyeang, ob.cit.: 438).

Según los $25 \%$ de los que han estudiado una imagen con sus docentes, trabajar con este tipo de documento «les queda muy atentos, dinámicos y curiosos» (alumnos de Tle).

Para $75 \%$ de los que nunca han aprendido el español a partir de una imagen, es lamentable. Finalmente esto plantea el problema de competencias en la disciplina. Desde su formación, el docente de lengua debería tener los rudimentos sobre el uso de todo tipo de documento. Desgraciadamente, en la práctica se nota un fallo debido a la falta de metodología en materia de explotación de imágenes en clase de ELE.

\section{MARCO PRÁCTICO}

\subsection{Sugerencias}

Para compensar la ausencia de soportes iconográficos en la enseñanza y el aprendizaje de las lenguas extranjeras, en general, y el español en particular, en el sistema educativo gabonés, formularemos dos principales sugerencias. La primera es institucional mientras la segunda es práctica o metódica.

\subsubsection{A nivel institucional}

Una de las razones que justifican el desequilibrio entre el uso de soportes textuales e iconográficos en Gabón es institucional. Así que para solucionar este problema que aísla el sistema educativo gabonés de su modelo francés, es imprescindible interesarse a estos fallos institucionales. El primer fallo que notamos mientras llevamos este estudio es la falta de concertación entre las instancias pedagógicas gabonesas que dictan las orientaciones teóricas que deben aplicarse en todo el país, y las escuelas que deben aplicar dichas orientaciones. Al acercarnos de cado uno de estos actores, nos damos cuenta de que, las instancias pedagógicas gabonesas, los docentes disponen de orientaciones suficientes para guiarles en sus prácticas de clase. Al contrario, para los docentes, las orientaciones dadas por las instancias pedagógicas nacionales son insuficientes dado son mucho más teóricas que practicas. A partir de estas dos posturas, pensamos que al reanudar el contacto entre ambas entidades, se podrá solucionar el problema de la escasez de la iconografía en la enseñanza/aprendizaje de ELE en Gabón. En efecto, para que las orientaciones sean eficaces, deben ser elaboradas en simbiosis entre las instancias pedagógicas y los docentes que deben aplicarlas. 
Otra dificultad institucional es a nivel de la formación de los profesores de lenguas extranjeras en Gabón. Si tomamos el caso del departamento de español de la Escuela Normal Superior (ENS) ${ }^{7}$, es de notar la presencia efectiva de enseñanzas relativas a la iconografía (H. Ndzang Nyangone, 2018:291). Sin embargo, la dificultad viene de los docentes que se encargan de dichas enseñanzas. En efecto, por carecer de especialistas en pedagogía por la imagen, la escuela encargó estas enseñanzas a los no especialistas. Por consiguiente, las formaciones propuestas se revelan incompletas e ineficaces para que los alumnos-profesores puedan dominar los soportes iconográficos. Desde poco, la ENS reclutó a unos especialistas para compensar esta dificultad. No obstante, y a pesar de la presencia de especialistas formados en análisis de la imagen, los voluntarios no formados que se encargan de esta formación desde años siguen impartiéndolas en nombre de los grados y de la duración en la docencia (Ibid:293). Para que los profesores de lenguas en formación no eviten la iconografía, proponemos que su formación sea obra de docentes formados en pedagogía por la imagen.

Así a partir de lo que acabamos de comentar, para más práctica de la lengua en clase de ELE, tenemos que sugerir unas pistas para mostrar la importancia del documento iconográfico como soporte didáctico.

\subsubsection{A nivel de las prácticas}

A nivel práctico, se debe inculcar a los alumnos-profesores de lenguas extranjeras de Gabón que la lectura o la interpretación de un documento iconográfico necesite las mismas capacidades y esfuerzos intelectuales que toda lectura. En efecto, pensar que la interpretación de un documento iconográfico no necesita ningún esfuerzo intelectual es rechazar el carácter comunicacional de la imagen (la iconografía). Para evitar las amalgamas, la enseñanza en iconografía debe ser metódica. Pues la misión primera de una imagen es testificar las realidades de su tiempo (E. Ethis, 2007, 77). Por eso, la imagen debe ser analizada e interpretada del mismo modo que lo hacemos con los textos. Entendemos por análisis, una operación que consiste en descuartizar la imagen en sus elementos esenciales para dar un esquema del conjunto (A. Rey, 2005). Al proceder así, se evita lo que se designa por «tentation iconique», es decir:

Ce besoin que nous avons, dès que nous sommes devant un message visuel (image), de chercher à «reconnaître» des «objets du monde (...) nous «sautons» immédiatement dans le contenu iconique du message, oubliant le plan de son expression, ainsi que les dimensions plastiques du message, pour pouvoir dire «c'est ceci ou c'est cela», et avoir ainsi l'impression de «comprendre(Martine Joly, 2002:132).

Además, reconocer los objetos del mundo en una imagen no es necesariamente sinónimo de su análisis. En efecto, entre el reconocimiento de los objetos y el análisis de una imagen, hay una serie de parámetros que pueden fácilmente escapar a los lectores no formados (H. Ndzang Nyangone, 2018).

Reconnaître» ne veut pas dire «comprendre»: il faut passer de la reconnaissance des formes à l'interprétation qui est une étape supplémentaire dans la compréhension et demande de connaître (même implicitement) les conditions de production et de diffusion, les symboles d'une société donnée, bref, le contexte culturel de la représentation et de la communication visuelle, pour passer de l'iconique au symbolique, de la dénotation à la connotation (Martine Joly, 2002:197).

Para salir de estos tópicos que pretenden que la interpretación de documentos iconográficos es inútil en pedagogía, es necesario que los formadores de los docentes de lenguas extranjeras de Gabón les inicien realmente a la lectura y a la interpretación de las imágenes. En efecto, como lo afirma más bien Martine Joly (Ibid.: 199):

L'analyse, même minimale peut contribuer à borner et à étoffer en même temps l'interprétation des images: la borner en confrontant ses conclusions au contenu et à l'organisation même de l'œuvre par une interprétation intrinsèque et l'étoffer en la nourrissant non seulement d'éléments prélevés en son sein, dans le texte, le corps de l'œuvre, mais aussi dans son contexte d'apparition et de décryptage, par une interprétation extrinsèque.

\footnotetext{
${ }^{7}$ Fundada en 1971, la ENS es especializada en la formación de los profesores del primer y del segundo del segundario. Esta misma escuela forma también a inspectores de la educación así como a los consejeros de orientación y otros actores del sistema educativo.
} 


\section{DISCUSIÓN Y CONCLUSIONES}

Para la discusión retenemos el tema cuyo título es «La imagen como apoyo didáctico en el aprendizaje de ELE en Gabón». Hemos elegido este tema porque en las entrevistas, los alumnos solían confesar que la imagen es un soporte que les anima mucho. Unos decían que si hubiera escogido entre un texto y un documento iconográfico, claro que elejerían el segundo soporte. Por eso, se puede decir que:

Sería difícil imaginar un contexto de enseñanza de idiomas sin el apoyo pedagógico de tarjetas ilustradas, murales con gráficos, imágenes de los libros de texto, fotografías descargables, líneas temporales, dibujos en la pizarra, diseños realizados por los alumnos, y mucho más (B. Goldstein, 2013: 1).

Ya que: «lo que estimula la reacción emocional para la comprensión, es la imagen asociada con palabras en nuestra mente» (Arnold, 2000: 281).

En las clases de español como lengua extranjera (E/LE) o segunda lengua (L2), la imagen es una herramienta utilizada por el docente como recurso didáctico de diversas formas: como material de apoyo, como introducción de una actividad, como parte central de una tarea, para trabajar la interculturalidad, de forma específica con un objetivo marcado, sin concretar el objetivo o para su propio divertimento, etc. (N. Barrallo Busto y M. Gómez Bedoya, 2009:1)

Esto para decir que «la importancia de la imagen en el proceso de aprendizaje de una lengua extranjera (LE) está relacionada con la capacidad humana para crear imágenes mentales a través de visualizaciones que atraigan nuestra atención, que nos estimulen, o nos provoquen emoción. En el estudiante de LE esto significa una mayor implicación y una mejor asimilación de la lengua objeto» (N. Barrallo Busto, ob.cit.: 2). También persigue diciendo que:

Las imágenes evocan recuerdos, pues hacen que los estudiantes las relacionen con etapas o sucesos en su vida, en el ejemplo anterior del coche, el estudiante de LE se imaginará el coche de su familia, de su novio, el coche de sus sueños, etc. Este factor favorece la motivación en el aula, pues permite crear un ambiente agradable, disminuir la ansiedad, y aumentar la concentración y la participación. Las representaciones visuales también albergan innumerables posibilidades de llamar la atención de los alumnos, se pueden unir a actividades lúdicas, que reducen el miedo a los errores, se pueden utilizar para crear situaciones reales de comunicación o simplemente acercar al profesor y a los estudiantes como grupo, creando un ambiente distendido y ameno en la clase (Ibid.: 3).

La situación que está describiendo Barrallo Busto, los alumnos entrevistados los habían vivido durante las clases de lengua. Para ellos, es fácil interpretar una imagen, porque les envían en situaciones ya vividas o que tienen la ambición de vivir. Con las imágenes son capaces de describir la continuación de la historia con más facilidad.

A modo de conclusión, exponemos en este trabajo, algunas de las conclusiones más significativas de este estudio atendiendo a las disposiciones oficiales de la enseñanza/aprendizaje de las lenguas extranjeras tanto en francia como en Gabón. Así que hemos podido averiguar nuestra hipótesis según la cual notamos cierta distancia entre Francia y Gabón en cuanto a la toma en cuenta de las instrucciones oficiales sobre el aprendizaje de las lenguas extranjeras. En efecto, el respeto del MCERL se nota claramente en los contenidos usados en los manuales de Francia. En éstos todo viene explicado, desde la metodología hasta cómo usarla. Al contrario en Gabón, se prevee la explotación de imágenes, pero sin decir cuál es el camino que seguir para alcanzar la meta.

Con respecto a las entrevistas semidirigidas, se destaca claramente que el uso de imágenes en clase de ELE en Gabón es casi inexistente, o cuando existe, los docentes no tienen la metodología adecuada.

La consecuencia es que explotan este tipo de documento superficialmente. Es decir aunque exista disposiciones oficiales que les otorgan a usar las imágenes, la ausencia de método hace que sea inexplotado. 
Luego relevamos durante las entrevistas semidirigidas, cierto entusiasmo por parte de lo poco que ya había explotado un documento iconográfico. Por eso, los docentes gaboneses tienen que concretar las instrucciones oficiales para un mejor aprendizaje del español en Gabón.

\section{REFERENCIAS BIBLIOGRÁFICAS}

ARNOLD, Jane. y al. (2000): La dimensión afectiva en el aprendizaje de idiomas. Colección Cambridge de didáctica de lenguas. Cambridge.

BARRALLO BUSTO, Natalia y al. (2009): «La explotación de una imagen en la clase de ELE», redELE (revista electrónica de didáctica/español lengua extranjera) in, [https://www.mecd.gob.es/dam/jcr:19942320-87bd-4889-821e-77b2831ab48c/2009-redele-16-01 barrallo-pdf.pdf], consulté, le 31/05/2018.

EYEANG, Eugénie y IBINGA, Marcelle (2013): «Reflexiones didácticas sobre el uso de la prensa en clase de español lengua extranjera», in Prensa pedagógica y patrimonio histórico educativo, Aquilafuente, Ediciones Universidad de Salamanca.

GOLDSTEIN, Ben (2013): El uso de imágenes como recurso didáctico, traducción de José María Ruiz Vaca, Madrid, Editorial Edinumen.

IBINGA, Marcelle y EYEANG Eugénie (2014): «Influencias de los trabajos de Montessori en la enseñanza/aprendizaje de las lenguas extranjeras en Gabón.

EYEANG Eugénie (1997): L'enseignement/apprentissage de l'espagnol au Gabon. Éléments de recherches pour une adaptation socio-didactique, Thèse de doctorat, Université de Grenoble III, Volume 1.

ETHIS Emmanuel (2007), Sociologie du cinéma et ses publics, Paris, Armand Colin.

GOLLIOT-LETE Anne et VANOYE Francis (2009), Précis d'analyse filmique, Paris, Nathan.

GOLLIOT-LETE Anne, JOLY Martine, LANCIEN Thiery et al. (2006), Dictionnaire de l'image, Paris, Vuibert.

JOLY Martine A (2002), L'image et les signes, Paris, Nathan.

JOLY Martine B (2002), L'image et son interprétation, Paris, Nathan.

LENGARA Cristian (2013), (A prendre dans mémoire YAPASSI).

NDZANG NYANGONE Hilaire (2018), «La diversification des supports pédagogiques au Gabon: quelle place pour l'iconographie», Sophos $n .^{\circ} 3$, Yaoudé, Edi-Cad, p.284-310.

NDZANG NYANGONE, H. (2018): La pédagogie par l'image au Gabon: théorie, méthodologie et pratique, Libreville, Éditions au gré des vagues.

NDZANG NYANGONE Hilaire (2018): «L'encadrement des recherches en iconographie à l'ENS de Libreville: les raisons d'un échec programmé», in Marcelle Ibinga et Mexcent Zue Elibiyo, Production scientifique au Gabon: tentative de réponse au questionnements sociaux, Paris, Publibook. 
NDZANG NYANGONE Hilaire (2014), «La imagen como soporte didáctico necesario a la enseñanza de ELE. El caso de El coctel de engaño de Didier Ebane Allogho y Medias sexualmente transmisibles de Lybek», Lengua, literatura y ciencia de la educación en los sistemas educativos del África subsahariana, Salamanca, Aquilafuente.

YAPASSI Mireille (2017) El cine como soporte didáctico para dinamizar la clase de ELE en Gabón, Memoria de Máster profesional, ENS-Libreville. 